\title{
QUINIDINE THERAPY AFTER MITRAL VALVOTOMY \\ BY
}

\author{
CLIVE P. ABER \\ From Liverpool Royal Infirmary
}

(RECEIVED FOR PUBLICATION FEBRUARY 8, 1962)

Nearly half a century has passed since quinidine was first used to convert atrial fibrillation to regular sinus rhythm in man (Frey, 1918). There is general agreement nowadays that the cardiorespiratory benefits resulting from the successful reversion of long-standing atrial fibrillation to sinus rhythm are worth the risk of quinidine therapy (Hay, 1924; Stroud, LaPlace, and Reisinger, 1932; Kohn and Levine, 1935). However, the published indications, results, and incidence of toxic effects from the use of quinidine in heart disease still vary considerably (Viko, Marvin, and White, 1923 ; Wolff and White, 1929 ; McMillan and Welfare, 1947 ; Gold, 1950 ; Hecht, Osher, and Samuels, 1951 ; Holzman and Brown, 1951; Yount, Rosenblum, and McMillan, 1952; Freeman and Wexler, 1960).

Several attempts have been made to assess the value of this drug in specific forms of heart disease, but opinions differ on factors influencing the response of long-standing atrial fibrillation to quinidine. The age of the patient, the aetiology of the heart disease, the presence of cardiac failure or cardiomegaly, and the duration of the arrhythmia have all been considered (Viko et al., 1923 ; Wolff and White, 1929; Harris, 1929 ; McMillan and Welfare, 1947; Holzman and Brown, 1951 ; Sokolow and Ball, 1956).

In recent years atrial fibrillation has been found to be one of the most frequent post-operative complications following mitral valvotomy in patients previously in sinus rhythm (Logan and Turner, 1953 ; Sellors, Bedford, and Somerville, 1953 ; Dimond and dos Santos, 1954; Wood, 1954 ; Goodwin, Hunter, Cleland, Davies, and Steiner, 1955; Heinz and Hultgren, 1957). Reasons for the development of this are still uncertain. Trauma to the left atrium, traumatic pericarditis, associated or surgically induced mitral incompetence, active rheumatic myocarditis, and electrolytic alterations have all been considered but not proven. There is some evidence to suggest that adequate use of digitalis and quinidine after operation helps to prevent arrhythmia developing (Kittle and Crockett, 1959). Fortunately, reversion to sinus rhythm can be accomplished with quinidine therapy in a very high percentage of these patients (Logan and Turner, 1953; Dimond and dos Santos, 1954 ; Wood, 1954 ; Goodwin et al., 1955 ; Heinz and Hultgren, 1957). On the other hand, postoperative attempts to revert and maintain sinus rhythm in patients who developed arrhythmia before valvotomy have met with very little success (Sellors et al., 1953; Wood, 1954; Kittle and Crockett, 1959).

The present investigation was designed to study the immediate and long-term effects of quinidine on both chronic and recently established atrial fibrillation in patients with dominant mitral stenosis who have had a recent mitral valvotomy. In addition, an attempt has been made to predict the likelihood of achieving reversion to sinus rhythm in both these groups of patients from (a) the electrocardiographic pattern of atrial activity, and $(b)$ the radiological size of the left atrium.

\section{MATERIAL AND Methods}

Fifty-eight patients (46 women and 12 men) with rheumatic mitral stenosis were submitted to mitral valvotomy. Their average age was 41.9 years (range 18 to 60 years). Those with significant aortic valve disease or mitral incompetence of any magnitude, as judged by clinical, radiological, phonocardiographic, and electrocardiographic criteria, were not included. Final assessment of the mitral valve was made on thoracotomy and/or cardiotomy.

The patients were divided into two groups, $\mathrm{A}$ and B. Group A consisted of 35 patients who were known to have been in atrial fibrillation before valvotomy. The average known duration of atrial fibrillation in this group was 26.5 months (range 1 month to 10 years). Twenty-one $(61.7 \%)$ of these patients had had the arrhythmia for 12 months or longer. Group B consisted of 23 patients who had all been in sinus rhythm before operation, but in whom atrial fibrillation developed in the immediate post-operative period, usually between the second and fifth post-operative days (range first to tenth day). 


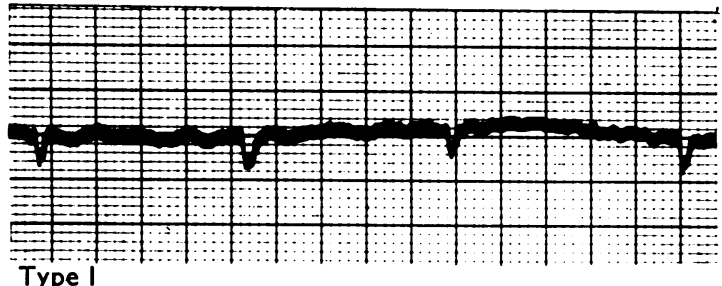

Type 1

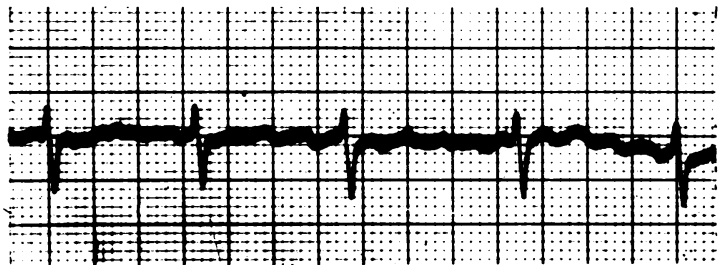

Type II

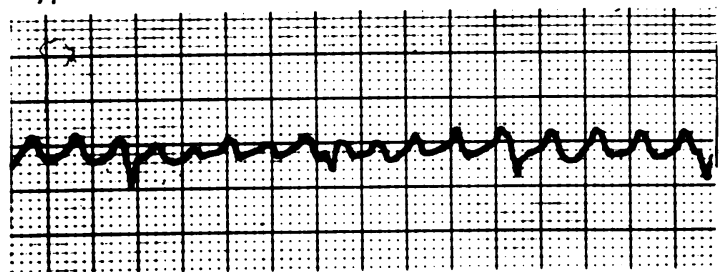

Type III

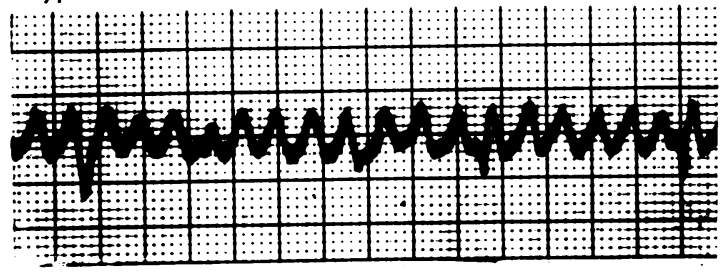

Type IV

FIG. 1.-Electrocardiographic patterns of atrial fibrillation in mitral stenosis $\left(C R_{1}\right.$ lead $)$.

A conventional pre-operative 12-lead (unipolar and bipolar) electrocardiogram was recorded from all the patients in this series on admission to hospital. An additional long strip (CR, lead) was recorded when atrial fibrillation was evident (Evans, 1941). Particular attention was paid to the " $P$ " wave configuration and size when present before the onset of the arrhythmia in group B (Mounsey, 1960), and an attempt was made to grade the regularity and amplitude of the electrocardiographic atrial pattern, as observed in the CR, strip (Fig. 1), according to the following criteria:

Type I "atrial pattern": There were no oscillations due to atrial activity.

Type II "atrial pattern": The oscillations due to atrial activity were visible but irregular and of small amplitude.

Type III "atrial pattern": The oscillations due to atrial activity were more regular and of larger amplitude.
Type IV "atrial pattern": The oscillations due to atrial activity were very regular and of large amplitude.

These patients are in broad groups and are not intended to represent ranges of precise measurements.

Radiological left atrial enlargement was graded as follows :

Grade 1: The left auricular appendage was just visible on the left cardiac border in the P.A. film, with minimal backward displacement of the bariumfilled oesophagus in the right anterior oblique film (Figs. 2a and b).

Grade 2: The left auricular appendage was visible on the left cardiac border on the P.A. film, and the contour of the left atrium was also just visible at the right cardiac border. There was definite backward displacement of the oesophagus in the right anterior oblique view (Figs. 3a and $b$ ).

Grade 3: There was marked prominence of the left atrium on the left and right cardiac borders and considerable backward displacement of the oesophagus. This included aneurysmal enlargement of the left atrium (Figs. 4a and b).

The ventricular rate was controlled with digitalis before quinidine therapy was started, and care was taken to ensure that the serum electrolytes were all normal. Supplementary potassium chloride was given to all patients on diuretics. This preliminary caution was observed because I have noticed that in the presence of hypokalaemia it is sometimes possible to convert both types I and II atrial activity to type III by administering oral potassium chloride. A "test dose" of quinidine sulphate $(0.2 \mathrm{~g}$.) was then administered on the twelfth to fourteenth postoperative day, since it was considered that future spontaneous reversion to sinus rhythm would be most unlikely to occur after this date, by which time the "trauma" of the surgical procedure would have settled down. On the following day $0.2 \mathrm{~g}$. of quinidine sulphate was given every two hours for nine doses. If this first course of quinidine failed to effect reversion to normal sinus rhythm and no toxic effects had been observed, $0.4 \mathrm{~g}$. of quinidine sulphate was administered every two hours for eight doses or until reversion to sinus rhythm occurred or toxic symptoms developed. If reversion was achieved, $0.4 \mathrm{~g}$. of quinidine was given every six hours. In four instances a third course of quinidine, similar to the second, was given.

\section{RESULTS}

Conversion Rate (Table I).--Of the 58 patients (groups A and B) treated with quinidine, 35 (72\%) reverted to a regular sinus rhythm ( 28 women and 7 men). Fourteen ( $40 \%$ ) were from group A (preoperative fibrillators), and $21(60 \%)$ were from group B (post-operative fibrillators).

In group $A$ the pre-valvotomy duration of atrial fibrillation bore little relationship to the conver- 


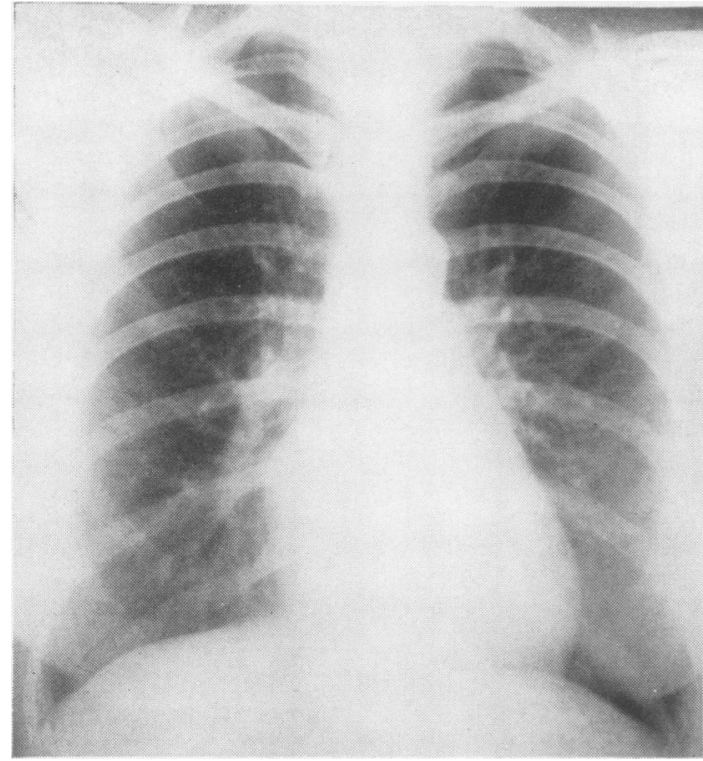

FIG. 2a.-Grade 1 enlargement of the left atrium (P.A. film).

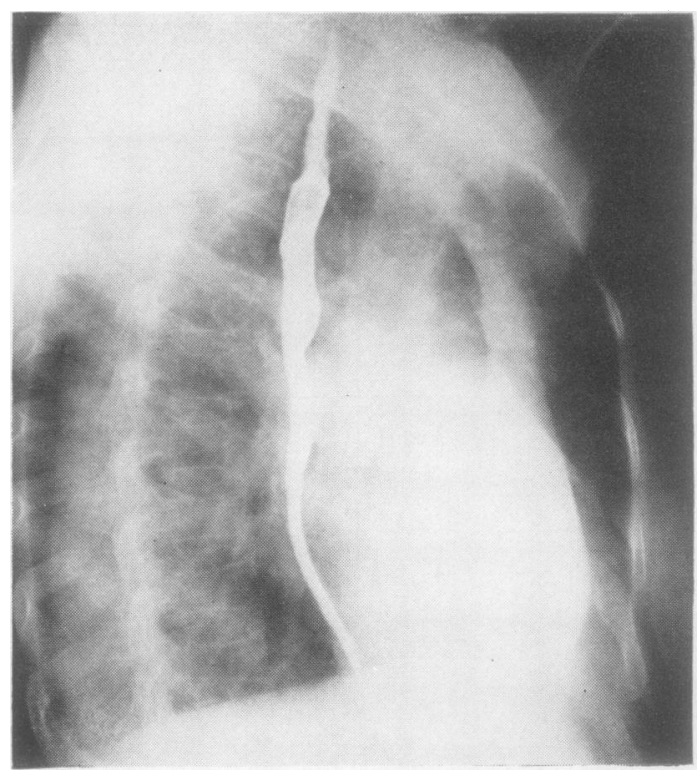

FIG. 2b.-Grade 1 enlargement of the left atrium (R.A.O. film).

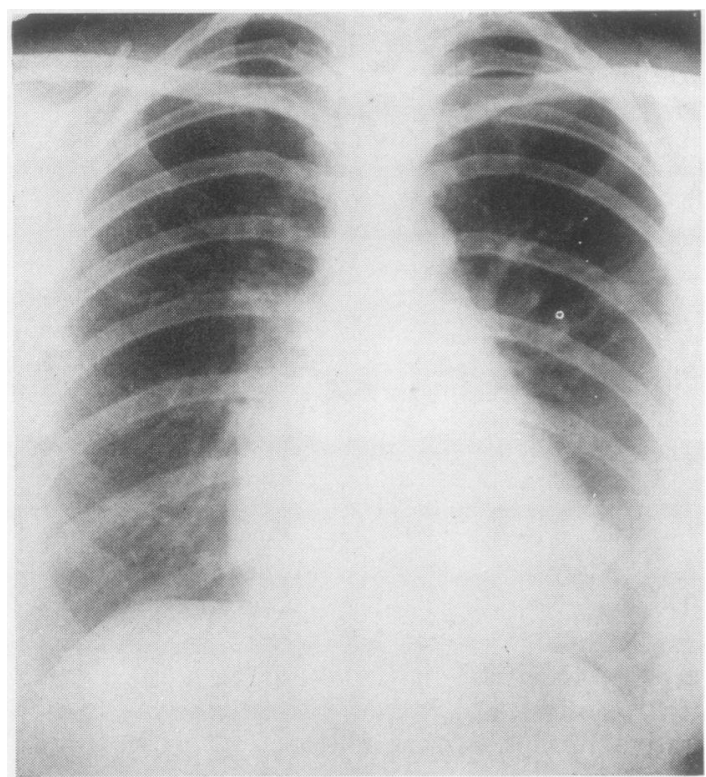

FIG. 3a.-Grade 2 enlargement of the left atrium (P.A. film).

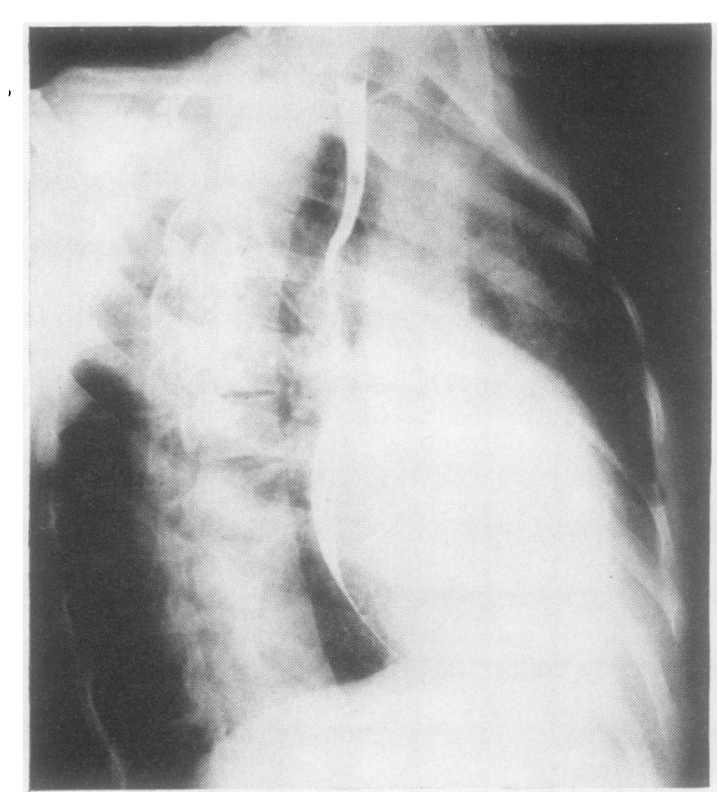

FIG. 3b.-Grade 2 enlargement of the left atrium (R.A.O. film). 


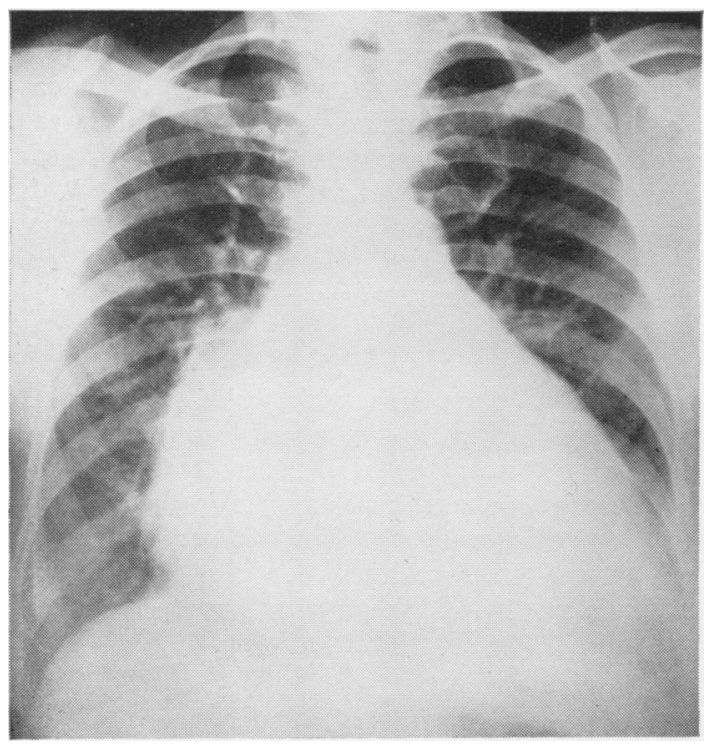

FIG. 4a.-Grade 3 enlargement of the left atrium (P.A. film).

TABLE I

CONVERSION RATE RELATIVE TO THE DURATION OF ATRIAL FIBRILLATION

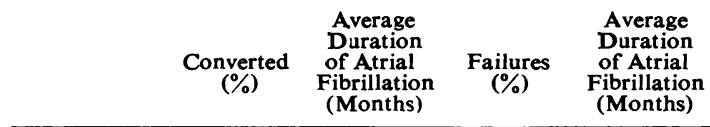

\begin{tabular}{ccccc}
\hline $\begin{array}{c}\text { Group A } \\
\text { (35 patients) }\end{array}$ & $\begin{array}{c}40 \cdot 0 \\
\text { (14 patients) }\end{array}$ & $26 \cdot 5$ & $\begin{array}{c}60 \cdot 0 \\
\text { (21 patients) }\end{array}$ & $22 \cdot 3$ \\
$\begin{array}{c}\text { Group B } \\
\text { (23 patients) }\end{array}$ & $\begin{array}{c}95 \cdot 5 \\
\text { (21 patients) }\end{array}$ & - & $\begin{array}{c}4 \cdot 5 \\
\text { (2 patients) }\end{array}$ & -
\end{tabular}

sion rate as 12 of these patients had had arrhythmia for over one year, eight for over two years, and three for more than five years before operation.

Twenty-one patients from group B (95.5\%) reverted to sinus rhythm.

No instance of spontaneous reversion to sinus rhythm was observed in this series.

The average age of the patients who reverted to sinus rhythm was 41.3 years, whereas the average age of those who failed to revert was 42.0 years.

Quinidine Dosage (Table II).-The average total amount of quinidine sulphate administered

TABLE II

AVERAGE DOSE OF QUINIDINE ADMINISTERED

\begin{tabular}{lcccc} 
& $\begin{array}{c}\text { Group } \\
\text { A }\end{array}$ & $\begin{array}{c}\text { Group } \\
\text { B }\end{array}$ & $\begin{array}{c}\text { Patients } \\
\text { Converted } \\
\text { to Sinus } \\
\text { Rhythm }\end{array}$ & $\begin{array}{c}\text { Patients } \\
\text { Failing } \\
\text { to Revert } \\
\text { to Sinus } \\
\text { Rhythm }\end{array}$ \\
\hline $\begin{array}{c}\text { Quinidine } \\
\text { (g. per patient) }\end{array}$ & $\begin{array}{c}3.9 \\
0.4-8.0)\end{array}$ & $\begin{array}{c}2.9 .4 \text { (range } \\
0.4 .3)\end{array}$ & $\begin{array}{c}2.6 \text { (range } \\
0.4-7.1)\end{array}$ & $\begin{array}{l}4.8(\text { range } \\
1.0-8.3)\end{array}$
\end{tabular}

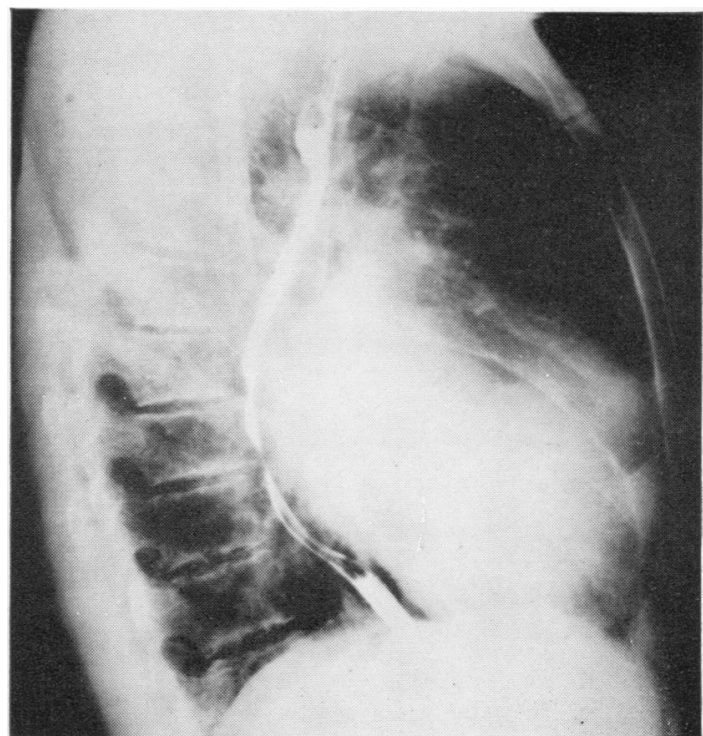

FIG. 4b.-Grade 3 enlargement of the left atrium (R.A.O. film).

per patient was $3.6 \mathrm{~g}$. The average quantity given to each patient in group B was less than in group A. Similarly, the average dose given to those patients who reverted to sinus rhythm was less than that given to those who failed to revert.

In three patients from group A, despite their having been in atrial fibrillation for over two years, a relatively small dose of quinidine was required to effect a reversion to sinus rhythm $(0.4$, 0.6 , and $1.2 \mathrm{~g}$. respectively).

E.C.G. Changes.-Particular attention was paid to the following.

Relationship of the E.C.G. Pattern of Atrial Activity to the Conversion Rate.-The electrocardiographic pattern of atrial activity bore a distinct relationship to the conversion rate (Table III). In patients with types I and II atrial pattern there was a $100 \%$ failure to revert to sinus rhythm, whereas 24 patients $(80 \%)$ with type III and 11 patients $(73.5 \%)$ with type IV atrial pattern were converted to sinus rhythm.

TABLE III

CONVERSION RATE RELATIVE TO THE ELECTROCARDIOCONVERSION RATE RELATIVE TO THE ELECTROCARDIO-

\begin{tabular}{ccc}
$\begin{array}{c}\text { E.C.G. Atrial } \\
\text { Pattern } \\
\left(\mathrm{CR}_{1} \text { Lead) }\right.\end{array}$ & $\begin{array}{c}\text { Converted } \\
(\%)\end{array}$ & $\begin{array}{c}\text { Failures } \\
(\%)\end{array}$ \\
\hline $\begin{array}{c}\text { Types I and II } \\
\text { (13 patients) }\end{array}$ & 0 & 100 \\
$\begin{array}{c}\text { Type III } \\
\text { (30 patients) }\end{array}$ & $\begin{array}{c}80 \cdot 0 \\
(24 \text { patients) } \\
73 \cdot 5\end{array}$ & $\begin{array}{c}20 \cdot 0 \\
(6 \text { patients) }\end{array}$ \\
$\begin{array}{c}\text { Type IV } \\
\text { (15 patients) }\end{array}$ & $(11$ patients) & $(4$ patients)
\end{tabular}


Two of the six patients with type III and three of the four patients with type IV " atrial pattern" who failed to revert to sinus rhythm had to stop quinidine therapy owing to severe gastro-intestinal upsets (vomiting and/or diarrhoea). The other patient with type IV " atrial pattern" who failed to revert to sinus rhythm received only $1.8 \mathrm{~g}$. of quinidine because he was prematurely discharged from hospital.

All the 13 patients who had either type I or type II " atrial pattern" were in group A.

" $P$ " Wave Pattern.-The shape and size of the " $P$ " waves in the electrocardiograms recorded from patients in group B bore no relationship to either the incidence of arrhythmia after valvotomy or the ease with which reversion to sinus rhythm was subsequently established.

LefT ATRIAL Size.-The pre-fibrillation atrial size bore no definite relationship to the incidence of atrial fibrillation after valvotomy (Table IV). Similarly, no relationship was observed between the left atrial size and either the ease with which sinus rhythm was restored or the electrocardiographic "atrial fibrillation pattern" in this group.

Type I or II patterns of atrial activity were usually associated with a large left atrium (Table V).

TABLE IV

LEFT ATRIAL SIZE IN GROUPS A AND B

\begin{tabular}{ccc}
$\begin{array}{c}\text { Left Atrial } \\
\text { Size }\end{array}$ & $\begin{array}{c}\text { Group A } \\
\text { (35 Patients) }\end{array}$ & $\begin{array}{c}\text { Group B } \\
(23 \text { Patients) }\end{array}$ \\
\hline Grade I & $2(5 \cdot 7 \%)$ & $5(21 \cdot 7 \%)$ \\
, II & $20(57 \cdot 0 \%)$ & $12(52 \cdot 2 \%)$ \\
, III & $13(37 \cdot 3 \%)$ & $6(26 \cdot 1 \%)$
\end{tabular}

TABLE V

LEFT ATRIAL SIZE RELATIVE TO THE E.C.G. ATRIAL PATTERN

\begin{tabular}{cccc}
$\begin{array}{c}\text { E.C.G. } \\
\text { “Atrial } \\
\text { Pattern" }\end{array}$ & \multicolumn{3}{c}{ Left Atrial Size } \\
\cline { 2 - 4 } & Grade 1 & Grade 2 & Grade 3 \\
\hline $\begin{array}{c}\text { Types I and II } \\
\text { Type III II } \\
\text { Type IV }\end{array}$ & -4 & 4 & 9 \\
Tyy & 3 & 8 & 6
\end{tabular}

INCIDENCE OF Toxic EFFects.-Six patients (10.4\%) experienced such toxic effects that quinidine had to be stopped. In four patients there was severe vomiting, and in two both vomiting and diarrhoea were the cause of trouble. Toxic electrocardiographic changes, especially prolongation of the QRS complex beyond $25 \%$, were not observed. Invariably these severe gastrointestinal symptoms developed during the first course of quinidine.

Follow-UP.-Follow-up data are available in 30 of the 35 patients restored to sinus rhythm
(10 from group A and 20 from group B). Twenty $\overrightarrow{\overrightarrow{\vec{s}}}$ five $(80.3 \%)$ have remained in sinus rhythm (seven from group A and 18 from group B). The average duration of maintenance of sinus rhythm was $10 \overline{\bar{s}}$ months (range one month to one and a half years) Four of these patients, all from group A, had been in atrial fibrillation for over 12 months, and two for over two years before operation. Main $\overrightarrow{0}$ tenance quinidine therapy had usually been withdrawn gradually within three months of the restoration of sinus rhythm.

Of the five patients who failed to remain in sinus rhythm, two had relapsed into atrial fibrilla- $-\overrightarrow{-}$ tion after an upper respiratory tract infection $\tilde{i}$ There was no obvious reason for the return of the arrhythmia in the other three patients, too whom adequate maintenance therapy had been administered. All five patients, however, remainedes much improved by the valvotomy.

\section{Discussion}

These results confirm previous observations that it is possible to restore and maintain sinus rhythmo in a very high percentage of the patients with $\mathrm{N}$ mitral stenosis who develop atrial fibrillation the first time in the immediate post-operaties period. However, these findings conflict with earlier work (Sellors et al., 1953; Wood, 195\$ ; Kittle and Crockett, 1959) because they show that normal sinus rhythm can also be restored and maintained for a reasonable duration in an appreciable number of patients who had atrial fibrillation before operation. The explanation for this may be that in the present series a relatively large dose of quinidine was administered to each patient, none of whom had either significanto aortic valve disease or cardiomegaly, factors which ${ }_{-}^{\times}$ also might account for the singular absence of electrocardiographic evidence of quinidineo toxicity.

All the reasons for the better response too quinidine therapy in group B than in group A are not clear, but the relatively short time that theo atrial fibrillation had been present in the former group must be of some importance.

If we accept that reversion of long-standingN atrial fibrillation to sinus rhythm is beneficial, N maximum benefit can be provided to a substantial $\omega$ number of patients with mitral stenosis not only by performing a good valvotomy but also by reestablishing normal cardiac rhythm.

The results suggest that in mitral stenosis it is ${ }_{7}^{+}$ possible to predict with a high degree of accuracy from the electrocardiographic pattern of atrial迹 activity the likelihood of being able to restore $\frac{?}{\odot}$ 
regular sinus rhythm with quinidine after mitral valvotomy. Evans (1941) also employed the $C_{1}$ lead to analyse the atrial pattern in atrial fibrillation and found similar variations from patient to patient, though exactly what causes these variations is not known. It is tempting to suggest that in the presence of "atrial patterns" I and II the atrial walls exhibit little, if any, contractile movement. This might reflect a myocardium that has become thin and virtually without function because of chronic distension behind a stenosed valve and/or as a consequence of long-standing "rheumatic fibrosis" (rather than of "active rheumatism"). Since six patients in this series had "atrial patterns" I or II and yet had been fibrillating for less than three months, the duration of fibrillation alone is not always responsible for poor electrocardiographic atrial activity.

On the other hand, the apparent correlation between atrial size and "atrial pattern" types I and II in group A suggests that a very large left atrium is an important factor in preventing success with quinidine therapy in cases of chronic atrial fibrillation.

\section{SUMMARY}

Fifty-eight patients with mitral stenosis and atrial fibrillation were treated with quinidine after mitral valvotomy.

Reversion to sinus rhythm was achieved in $95 \%$ of the patients who developed atrial fibrillation for the first time immediately after valvotomy. Forty per cent. of those who had had the arrhythmia before operation also reverted and, of these, most had been fibrillating for over one year.
In both groups sinus rhythm was usually maintained for at least 10 months.

It was possible to predict the likelihood of achieving conversion to sinus rhythm from the electrocardiographic pattern of atrial activity but not from the left atrial size.

I should like to thank Mr. Ronald Edwards, Mr. J. Bickford, Mr. K. Waddington, Mr. L. J. Temple, and Mr. I. Morrison for permission to study their cases in the Liverpool Thoracic Surgical Centre, and Dr. W. S. Sutton and Dr. C. Ogilvie for their help while carrying out this investigation.

\section{REFERENCES}

Dimond, E. G., and dos Santos, E. M. (1954). J. Kans. med. Soc., 55,120 .

Evans, W. (1941). Brit. Heart J., 3, 247.

Freeman, I., and Wexler, J. (1960). Amer. J. med. Sci., 239, 181.

Frey, W. (1918). Berl. Klin. Wschr. 55, 450.

Gold, H. (1950). Quinidine in Disorders of the Heart. Hoeber, New York.

Goodwin, J. F., Hunter, J. D., Cleland, W. P., Davies, L. G., and Steiner, R. E. (1955). Brit. med. J., 2, 573.

Harris, K. E. (1929). Heart, 14, 283.

Hay, J. (1924). Lancet, 2, 543.

Hecht, H. H., Osher, W. J., and Samuels, A. J. (1951). J.clin. Invest., 30,647 .

Heinz, R., and Hultgren, H. (1957). A.M.A. Arch. intern. Med., 99, 896.

Holzman, D., and Brown, M. G. (1951). Amer. J. med. Sci., 222, 644.

Kittle. C. F., and Crockett, J. E. (1959). J. thorac. cardiovasc. Surg., 38,353 .

Kohn, C. M., and Levine, S. A. (1935). Ann. intern. Med., 8, 923.

Logan, A., and Turner, R. (1953). Lancet, 1, 1007 and 1057.

McMillan, R. L., and Welfare, C. R. (1947). J. Amer. med. Ass. $135,1132$.

Mounsey, P. (1960). Brit. Heart J., 22, 617.

Sellors, T. H., Bedford, D. E., and Somerville, W. (1953). Brit. med. J., 2, 1059.

Sokolow, M., and Ball, R. E. (1956). Circulation, 14, 568.

Stroud, W. D., LaPlace, L. B., and Reisinger, J. A. (1932). Amer. J. med. Sci., 183, 48.

Viko, L. E., Marvin, H. M., and White, P. D. (1923). Arch. intern. Med., 31, 345.

Wolff, L., and White, P. D. (1929). Ibid., 43, 653.

Wood, P. (1954). Brit. med. J., 1, 1113.

Yount, E. H., Rosenblum, M., and McMillan, R. (1952). A.M.A. Arch. intern. Med., 89, 63. 